pedagogical premise of his text, Dr Hughes derives almost nothing and therefore demands either that the student take a great deal on trust or that he spend a great deal of time on background material. My view of the matter is that Dr Hughes, less conventional by far, is nearer the mark of what our undergraduate teaching should be. We should try, above all else, to get over the physics sense, indicating clearly what is rigorously derivable and what is not, but eschewing detail, indicating sources for the appropriately involved student but not compelling him to digest extensive and soul destroying formalism that in the first place rests on unphysical approximations and in the second place does not lead to applications that carry his understanding further forward.

Both books are nicely and clearly printed and attractively laid out but the photographs (in Dr Hughes's book) are very sooty.

D. H. WILKINSON

\section{Early Medical Books}

Catalogue of Medical Books in Manchester University Library 1480-1700. Compiled by E. M. Parkinson, assisted by A. E. Lumb. Pp. 399. (Published on behalf of the Manchester University Library and the Manchester Medical Society.) (Manchester University: Manchester, May 1972.) $£ 15$.

MANCHESTER is or was famed for its cotton mills, its football-teams, its Ship Canal, its Free Trade Hall, its university, its orchestra, its rivalry with Liverpool (and jealousy of London), as well as for its libraries of which John Rylands is the jewel that outshines all others: a rather less sparkling stone, by comparison, being the library now so well catalogued in part by Mrs Parkinson and her aides.

The core of this valuable collection was put together by a few early members of the Medical Society (founded 1834) and was deposited with the University in 1870 . Since 1930 it has been administered, with accretions to it, as a part of the University Library and today it stands as probably the best of its kind in the English provinces. These basic facts are mentioned by the University Librarian in a preface in which he pays due credit to the chief benefactors of the past (for example, Christie, Parkinson, Bullock, Arnold). If we may be allowed one quibble, however, it seems a little unfortunate that the preface fails to acknowledge the short-title catalogue to the Society's library published in 1890 , the more so as it is bound to retain its usefulness until such time as a promised volume appears covering the 18 th and
19 th centuries. The preface might also have usefully identified those subjects in which the library is particularly strong (for example, deaf and dumb) and, if nothing else, its earliest book (Guy de Chauliac, Chirurgia, 1480). Looking to the future, it is good to learn that the pre-1701 medical books at Rylands will be included in a forthcoming catalogue of the University's History of Science collections.

The bibliographical and production standards reached in this volume of 2,685 entries are very high indeed. Titles and imprints are given fully; crossreferences are more than adequate; very few errors of transcription occur; contents of collective volumes are listed at great length (for example, Le Clerc's Bibliotheca anatomica, 1685); whilst forming a useful adjunct are indexes of subjects (selective), places, printers and publishers.

Most of the big names are represented. Anyone studying the Renaissance, for example, will be pleased to find Vesalius, Champier, Estienne, Cardano, as well as good crops of Galen (forty-three items) and Hippocrates (fifty-three) and the expected herbals by Dioscorides, Fuchs, Gerard, Parkinson, Dodoens, and Mattioli. For the 17th century there are ten Boyle items, thirtysix by Thomas Bartholinus, nine by Harvey (though not the 1628 De Motu), sixteen by Helmont, eleven by Salmon, sixteen by Glauber, Whistler on the rickets (1645), Glisson on the liver (1654), and much else besides. The index reveals only one book printed at Cambridge as against nineteen at Oxford, three at Prague, and two at Edinburgh-with Amsterdam, Basle, Frankfurt, Leyden, London, Paris and Venice taking the greatest number of entries.

The compilers are to be congratulated on a splendid achievement.

E. GASKell

\section{Antique Instruments}

Scientific Instruments of the Seventeenth and Eighteenth Centuries and their Makers. By M. Daumas. Pp. $361+142$ Plates. (B. T. Batsford: London, 1972.) $£ 10$.

IT must be made clear from the beginning that this is a translation of a book originally published in Paris in 1953, a fact nowhere stated in this English edition. It is also appropriate to point out that the French paperback edition is still available, and can be bought for 26 francs.

There are a number of reasons why the historian of science would prefer to use the French version: the name index includes dates when known, the notes and references are in their proper place at the foot of the page, it is more satisfactory to have the original twentyyear-old text rather than a partially revised one. By the nature of things, a considerable and pioneering thesis is not revisable. The original edition was produced at a time when interest was beginning to be taken in the history of scientific instruments, and it helped to quicken that interest, stressing as it does the social and economic factors as well as the industrial and technical ones. As a result, múch new knowledge has been acquired and new attitudes have developed, but little of it has yet been published in book form. Now is the time for a completely new assessment, which, if it were to achieve the same scope as M. Maurice Daumas's work, would fill several volumes. Today, one would certainly criticize M. Daumas for deliberately omitting sundial and globe makers. There is also the curious omission of any reference to the many prewar papers of von Rohr on the history of optical instruments.

In this English edition, one would have hoped for better sub-editing. The bibliography, now treble the original seventy items, does not contain all the works cited in the references, and, moreover, it has been only haphazardly brought up to date. Two important bibliographies on the history of astronomical and optical instruments, pub. lished in 1963 and 1969, are not included. Cross-referencing among the end notes can infuriatingly break down. For no good reason the two-page appendix is printed in French. The caption to Fig. 71 is a translation of the original caption, but the plate has been changed, so making nonsense. Fig. 141 is not of an Atwood fall-machine, but of an apparatus somewhat similar in appearance for the study of friction on an axle.

It may be that the publisher intended this book for collectors and the antiques trade, but the illustrations are not selected for this market, and the text certainly is not meant for it. It is difficult to imagine what useful purpose this English edition can serve, particularly at so high a price.

G. L'E. TURner

\section{Erratum}

WE apologize for an unfortunate error in the review "Planetary Exploration" (Nature, 238, 295; 1972), the book Geological Problems in Lunar and Planetary Research (AAS Publications: Tarzana, California, 1971) is not free but costs $\$ 19.75$. 